\title{
Cuidado parental de Sula leucogaster (Boddaert) (Aves, Pelecaniformes, Sulidae) nas llhas dos Currais, Paraná, Brasil
}

\author{
Flávia de Campos Martins ${ }^{1} \&$ Manoel Martins Dias ${ }^{2}$
}

1 Programa de Pós-Graduação em Ecologia, Instituto de Ciências Biológicas, Universidade de Brasília. Asa Norte, 70910-900 Brasília, Distrito Federal, Brasil. E-mail: flaatoba@yahoo.com.br

2 Departamento de Ecologia e Biologia Evolutiva, Universidade Federal de São Carlos. Caixa Postal 676, 13565-905 São Carlos, São Paulo, Brasil.

\begin{abstract}
Parental care in Sula leucogaster (Boddaert) (Aves, Pelecaniformes, Sulidae) on the Currais Islands, Paraná, Brazil. In Sula leucogaster (Boddaert, 1783) it happens a brood reduction from two to one egg. The eggs hatch asynchronously and it is rare for the second chick to survive for long. A quantify parental investment is proposed and the differences between males and females of Sula leucogaster is verified for to help to understand the brood reduction. The studies were conducted on Ilhas dos Currais, Paraná, Brazil, where a total of 140 nests were studied. Males and females shared the breeding care period. However, females invested about $8 \%$ more on incubation than males $\left(\chi^{2}=7,37 ; \chi^{2}\right.$ critic $\left.=3,842\right)$. Time of absence in the nest for females was larger than for males $\left(\chi^{2}=13,9 ; \chi^{2}\right.$ critic $\left.=3,842\right)$. This is probably a function of females bringing food to chicks more frequently $(61 \%, \mathrm{n}=120)$ than males $\left(\chi^{2}=5,63 ; \chi^{2}\right.$ critic $\left.=3,842\right)$. The main parental investment during the phases with eggs and/or hatchings was protection, and during the postfledging period was to provide feeding. The brood reduction in $S$. leucogaster is due to the high cost of rearing two chicks during the same breeding attempt. This could be a disadvantage to the future survival and/or the reproduction of both parents and chicks.
\end{abstract}

KEY WORDS. Breeding, brood reduction.

Investimento parental é qualquer comportamento dos pais que aumenta a probabilidade de um filhote sobreviver até a reprodução, às custas da capacidade dos pais de gerarem outros filhotes (Trivers 1972). Entre as aves, como na maioria dos outros animais, os sexos raramente investem na reprodução da mesma maneira. Geralmente os machos competem pelas fêmeas, sendo que o seu sucesso reprodutivo aumenta proporcionalmente com o número de cópulas, enquanto que o sucesso reprodutivo da fêmea freqüentemente aumenta com o investimento na prole (BATEMAN 1948, Trivers 1972, Clutton Brock 1991). Contudo, se a sobrevivência da prole estiver ameaçada, então o macho deverá se beneficiar ignorando outras possibilidades de acasalamento e investindo em cuidados com a prole (Maynard SMith 1977). Nas espécies com cuidado parental, o número de descendentes produzidos com sucesso numa estação reprodutiva não é, normalmente, limitado pelo número de ovos que uma fêmea pode colocar, mas pelo número de descendentes que os pais podem alimentar (LACK 1968).

O atobá-pardo, Sula leucogaster (Boddaert, 1783) (Pelecaniformes, Sulidae), é uma ave marinha que habita todos os oceanos tropicais, aproximadamente entre as latitudes $30^{\circ} \mathrm{N}$ e $30^{\circ} \mathrm{S}$. É o mais comum dos sulídeos na costa do Brasil (Sick 1997). Reproduz-se em colônias de tamanho e densidade variáveis. Ambos os sexos participam da construção do ninho, da incubação dos ovos e da alimentação dos filhotes (Dorward 1962, Nelson 1978, Simmons 1967). A espécie apresenta dimorfismo sexual na coloração dos pés, bico, partes nuas da pele e da mancha ocular (SIcK 1997). Fêmeas são maiores que os machos.

Sula leucogaster se reproduz contínua e desincronizadamente, ou seja, dentro da colônia verificam-se, praticamente, todos os estágios reprodutivos em todos os meses, embora picos reprodutivos sejam observados. Os ninhos são feitos no chão com gravetos e folhas secas, penas e algumas vezes com material antrópico (pedaços de isopor, nas ilhas dos Currais).

Nesta espécie ocorre o fenômeno de redução da ninhada, onde dois ovos são colocados e, na maioria das vezes, um filhote se desenvolve. Os ovos eclodem desincronizadamente. Segundo Nelson (1978), S. leucogaster é uma espécie fratricida obrigatória, ou seja, o primeiro filhote eclodido ataca e mata o irmão, independentemente dos recursos alimentares disponíveis. 
Considerando-se o cuidado parental como um provável fator que influencie a redução da ninhada e o sucesso reprodutivo de $S$. leucogaster, objetivou-se quantificar o investimento parental da espécie durante o ciclo reprodutivo, nas diferentes fases de desenvolvimento da ninhada. Além disso, buscou-se verificar diferenças no investimento parental entre machos e fêmeas, discutir como essas diferenças influenciariam o sucesso reprodutivo e como ajudariam a explicar o fenômeno de redução da ninhada nessa espécie.

\section{MATERIAL E MÉTODOS}

\section{Área de estudo}

As ilhas dos Currais $\left(25^{\circ} 44^{\prime} \mathrm{S}, 48^{\circ} 22^{\prime} \mathrm{W}\right)$ constituem um arquipélago formado por três ilhas separadas do continente por seis milhas náuticas do balneário Praia de Leste, município de Pontal do Paraná, centro-sul do litoral paranaense. A vegetação das Ilhas dos Currais, pobre floristicamente, enquadra-se na Formação Pioneira de Influência Marinha sobre o litoral rochoso (IBGE 1992). Nos pontos de solo mais raso, com afloramento de rocha, predominam comunidades herbáceas com menos de 1 metro de altura. As ilhas dos Currais são indicadas como área prioritária para conservação da Mata Atlântica e dos Campos Sulinos, na categoria de área de extrema importância biológica (MMA 2002).

A maior das ilhas, Grapirá, onde foram realizadas as amostragens, apresenta altitude máxima de 55 metros e 73.534 $\mathrm{m}^{2}$ de área total emersa; a encosta oeste possui declividade de $20^{\circ}$ e as encostas norte e leste de $28^{\circ}$. Há algumas áreas de menor declividade $\left(5\right.$ a $\left.9^{\circ}\right)$, outras de superfície plana e uma pequena praia de seixos. A espécie estudada estabelece colônia na porção da ilha com menor declividade, que foi, desse modo, utilizada como área amostral. A espécie também apresenta ninhos esparsos nas outras porções da ilha.

\section{Metodologia}

Foram realizadas 14 expedições no período de outubro de 1998 a dezembro de 1999, com duração de um a três dias cada. Nesse período foram marcados e acompanhados 140 ninhos, classificados em 10 fases: (1) um ovo; (2) dois ovos; (3) um filhote recém-eclodido e um ovo; (4) um filhote recémeclodido; (5) dois filhotes recém-eclodidos; (6) um filhote com penugem pós-natal branca e um filhote recém-eclodido; (7) um filhote com penugem pós-natal branca; (8) um filhote com plumagem castanha e restos de penugem branca; (9) um filhote com plumagem castanha, sem vestígios de penugem; (10) filhote abandona o ninho.

O método de observação utilizado foi o "Focal Sampling" (ou "Focal Animal Sampling") que Martin \& Bateson (1986) definiram como sendo a observação de um indivíduo ou grupo, por um período específico de tempo e registro de todos os instantes dos comportamentos. Esse é considerado o método mais satisfatório para estudar grupos. O método de registro utilizado foi o "Continuous Recording" (ou "All-ocorrences" recording). Esse método provê um registro exato e fiel do comportamento, medindo as reais freqüências e durações e as vezes em que os padrões comportamentais terminam e começam (MARTin \& Bateson 1986).

As observações foram feitas, em intervalos desde o amanhecer até o anoitecer, de uma pedra mais alta distando apro- ximadamente dois a três metros dos ninhos mais próximos e 10 a 12 metros dos ninhos mais distantes. Foram observados no mínimo três e no máximo 15 ninhos simultaneamente (média de nove ninhos) e anotadas as seguintes variáveis: (1) tempo de ausência do macho; (2) tempo de ausência da fêmea; (3) tempo de permanência do macho; (4) tempo de permanência da fêmea; (5) número de ofertas de alimento aos ninhegos realizadas pelo macho; (6) número de ofertas de alimento aos ninhegos realizadas pela fêmea.

Totalizaram-se 229,91 horas de observação. Utilizou-se o tempo total para os cálculos de 1728,68 horas/ninho, que correspondem ao tempo de observação multiplicado pelo número de ninhos observados ao mesmo tempo. Não foram feitas observações comportamentais dos ninhos na fase nove, já que o jovem não permanece o tempo todo no ninho.

Para comparar as diferenças no cuidado parental entre machos e fêmeas aplicou-se o teste de aderência do qui-quadrado, com um nível de significância estabelecido de 5\%. O teste de aderência do qui-quadrado é freqüentemente usado quando se tem uma amostra de escala nominal e deseja-se inferir se a população da qual foi retirada segue uma distribuição teórica específica (ZAR 1999). Neste caso a hipótese nula é se a distribuição do investimento (tempo) nas atividades de cuidado de machos e fêmeas é a mesma, ou seja, segue a distribuição teórica de $50 \%$ do tempo para cada sexo.

\section{RESULTADOS}

O período compreendido entre a fase de um ovo (fase um) até quando o filhote abandona o ninho (fase dez), teve duração média de 196 dias ( $\mathrm{n}=8$, com um desvio padrão de 35,1 dias). Ou seja, o período de cuidado parental é de cerca de seis meses e meio. Não observaram-se ninhos na fase seis.

\section{Incubação}

Machos e fêmeas se revezaram no choco a partir da primeira oviposição. A freqüência do tempo de incubação das fêmeas foi significativamente maior que aquela dos machos $\left(\chi^{2}=7,37 ; \chi^{2}\right.$ crítico $\left.=3,842\right)$. As fêmeas incubaram $54 \%$ do tempo (aproximadamente 569 horas/ninho) e os machos incubaram $46 \%$ do tempo (aproximadamente 481 horas/ninho). Essa diferença foi significativa nas fases com dois ovos (fase dois) $\left(\chi^{2}=10,95 ; \chi^{2}\right.$ crítico $\left.=3,842\right)$ e com um ninhego recémeclodido e um ovo (fase três) $\left(\chi^{2}=6,42 ; \chi^{2}\right.$ crítico $\left.=3,842\right)$. Somente na fase com um filhote recém-eclodido (fase quatro) os machos chocaram $16 \%$ do tempo a mais que as fêmeas, mas essa diferença não foi significativa (Tab. I).

\section{Vigilância e defesa do ninho}

$\mathrm{Na}$ maior parte do tempo de observação, estavam presentes nos ninhos os machos e/ou as fêmeas (97\% do tempo total). Durante o dia, machos e fêmeas se revezavam no mínimo duas vezes. Aparentemente o revezamento entre o casal não teve relação com o horário do dia, entretanto notou-se uma sincronização entre indivíduos do mesmo sexo nas saídas da colônia.

Do tempo de ausência de 3\% (50 horas/ninho), 3\% e 5\% aproximadamente corresponderam às fases um e dois respectivamente (Fig. 1). Nessas fases foram observadas as freqüências mais altas de falência dos ninhos: $41 \%$ e $37 \%$ respectivamente. Nas outras fases as freqüências de falência ficaram em torno de 
Tabela I. Tempo de incubação de machos e fêmeas de Sula leucogaster, nas ilhas dos Currais, Paraná, de outubro de 1998 a dezembro de 1999 e os respectivos resultados do teste qui-quadrado $\left(\chi^{2}\right)$. Fases dos ninhos: 1 (um ovo); 2 (dois ovos); 3 (um filhote recém eclodido e um ovo); 4 (um filhote recém-eclodido); 5 (dois filhotes recém-eclodidos).

\begin{tabular}{|c|c|c|c|c|c|}
\hline Fases & Tempo de incubação do macho $(\mathrm{h})$ & $\%$ & Tempo de incubação da fêmea (h) & $\%$ & $\chi^{2}$ \\
\hline 1 & 150 & 48 & 162 & 52 & $0,46 \mathrm{NS}$ \\
\hline 2 & 214 & 43 & 288 & 57 & $10,95^{*}$ \\
\hline 3 & 20 & 34 & 39 & 66 & $6,42^{*}$ \\
\hline 4 & 68 & 58 & 49 & 42 & $2,79 \mathrm{NS}$ \\
\hline 5 & 29 & 49 & 31 & 51 & $0,017 \mathrm{NS}$ \\
\hline Total & 481 & 46 & 569 & 54 & $7,37^{*}$ \\
\hline
\end{tabular}

$\chi^{2}$ crítico $=3,842,(\alpha=0,05 ; 95 \%) ;(N S)$ não significativo; $\left.{ }^{*}\right)$ significativo.

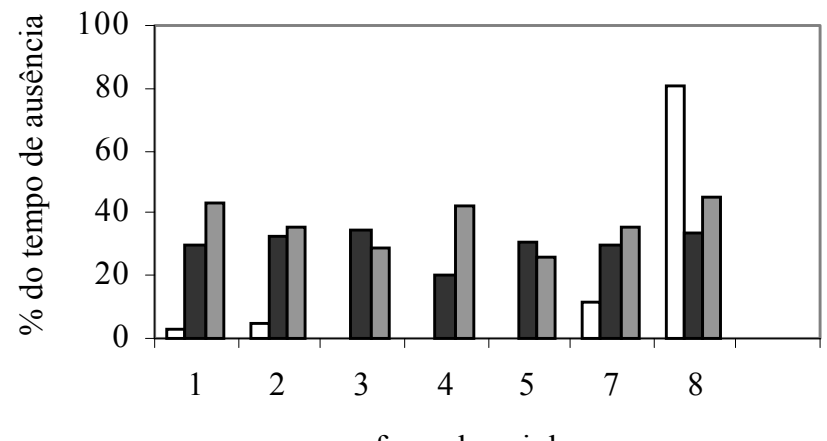

fases dos ninhos

$\square$ tempo de ausência total

tempo de ausência da fêmea

Figura 1. Porcentagem do tempo em que machos e fêmeas de Sula leucogaster ficaram ausentes do ninho, simultaneamente e alternadamente, nas ilhas dos Currais, Paraná, de outubro de 1998 a dezembro de 1999. Fases dos ninhos: 1 (um ovo); 2 (dois ovos); 3 (um filhote recém eclodido e um ovo); 4 (um filhote recémeclodido); 5 (dois filhotes recém-eclodidos); 7 (um filhote com penugem pós-natal branca); 8 (um filhote com plumagem castanha e restos de penugem branca).

4 a 7\%. Não houve ausência simultânea de machos e fêmeas nos ninhos com filhotes recém-eclodidos, fases três, quatro e cinco (Fig. 1). Houve também aumento da agressividade dos pais, contra invasores, nessas fases. Na fase sete, em que o filhote adquire penugem branca e já exibe comportamento de defesa, o tempo de ausência simultânea dos adultos foi cerca de $12 \%$ do tempo de ausência total (aproximadamente $6 \mathrm{~h} / \mathrm{ni}$ nho). Quando os filhotes iniciam sua muda para a plumagem juvenil, seu tamanho aumenta significativamente e ocorre maior tempo de ausência de ambos os pais, sendo $80 \%$ do tempo de ausência total ( $40 \mathrm{~h} /$ ninho), o que corresponde a aproximadamente $2 \%$ do tempo total de observação (Fig. 1).

Os machos permaneceram nos ninhos, aproximadamente, $69 \%(1.189 \mathrm{~h} / \mathrm{ninho})$ do tempo, enquanto que as fêmeas $61 \%(1.058 \mathrm{~h} /$ ninho) do tempo total, essa diferença foi estatis- ticamente significativa $\left(\chi^{2}=7,52 ; \chi^{2}\right.$ crítico $\left.=3,842\right)$. Nas fases três e cinco, as fêmeas permaneceram nos ninhos cerca de $6 \%$ e $5 \%$ do tempo, a mais que os machos, diferença não significativa. Em todas as outras fases os machos permaneceram no ninho mais tempo que as fêmeas, essa diferença foi significativa nas categorias um $\left(\chi^{2}=4,02 ; \chi^{2}\right.$ crítico $\left.=3,842\right)$ e quatro $\left(\chi^{2}=4,17 ; \chi^{2}\right.$ crítico $\left.=3,842\right)$ (Tab. II).

Foi verificada predação de ovos principalmente pelo gaivotão Larus dominicanus Lichtenstein, 1823 (Charadriiformes, Laridae) e em seguida pelo urubu-comum Coragyps atratus (Bechstein, 1793) (Ciconiiformes, Cathartidae).

\section{Alimentação dos filhotes}

Os adultos alimentaram a sua prole até a fase em que o jovem adquire plumagem juvenil, voa, mas ainda volta ao ninho. As ofertas de alimento eram desencadeadas por estímulos do filhote (vocalização), principalmente na fase de recémeclodido; nas fases seguintes, além da vocalização, o filhote desferia bicadas contra o bico do adulto; nas fases oito e nove essas bicadas eram insistentes.

Para obter alimento, os filhotes colocavam a cabeça dentro da garganta dos adultos, os quais, com movimentos de contração passavam o alimento para o bico dos filhotes, durante 10 a 30 segundos. Quanto menor o filhote mais digerido era o alimento; filhotes maiores recebiam o alimento em pedaços.

Os filhotes foram alimentados cerca de duas vezes por dia, principalmente a partir da fase sete, com penugem branca. Quando recém-eclodidos (fases quatro e cinco), os filhotes receberam $15,8 \%(n=19)$ das ofertas observadas, na fase sete $44,2 \%(\mathrm{n}=53)$ e na fase oito $40 \%(\mathrm{n}=48)$ das ofertas de alimento (Tab. III).

As fêmeas foram responsáveis por um maior número de ofertas de alimento aos filhotes $\left(\chi^{2}=5,63 ; \chi^{2}\right.$ crítico $\left.=3,842\right)$, realizaram $61 \%(n=73)$ das ofertas e os machos, $39 \%(n=47)$ das ofertas de alimento. Nas fases sete e oito, com maior número de alimentações, as fêmeas realizaram 11 e $12 \%$, respectivamente, mais alimentações que os machos. Tal diferença foi significativa apenas na fase oito $\left(\chi^{2}=4,08 ; \chi^{2}\right.$ crítico $\left.=3,842\right)$ (Tab. III).

No período da tarde ocorreram $81 \%(\mathrm{n}=98)$ e no período da manhã $19 \%(n=120)$ das ofertas de alimento aos ninhegos. Observaram-se dois picos de alimentação durante a manhã, um entre 9:30 e 10:00, com 4,1\% das ofertas de ali- 
Tabela II. Tempo em que machos e fêmeas de Sula leucogaster estiveram presentes nos ninhos, nas ilhas dos Currais, Paraná, de outubro de 1998 a dezembro de 1999 e os respectivos resultados do teste qui-quadrado $\left(\chi^{2}\right)$. Fases dos ninhos: 1 (um ovo); 2 (dois ovos); 3 (um filhote recém eclodido e um ovo); 4 (um filhote recém-eclodido); 5 (dois filhotes recém-eclodidos); 7 (um filhote com penugem pós-natal branca); 8 (um filhote com plumagem castanha e restos de penugem branca).

\begin{tabular}{cccccc}
\hline Fases & Tempo de permanência do macho $(\mathrm{h})$ & $\%$ & Tempo de permanência da fêmea $(\mathrm{h})$ & $\%$ & \multicolumn{1}{c}{$\chi^{2}$} \\
\hline 1 & 219 & 70 & 179 & $57,02^{*}$ \\
2 & 337 & 67 & 321 & 64 & $0,39 \mathrm{NS}$ \\
3 & 39 & 65 & 42 & 71 & $0,11 \mathrm{NS}$ \\
4 & 94 & 80 & 68 & 58 & $4,17^{*}$ \\
5 & 41 & 69 & 45 & 74 & $0,19 \mathrm{NS}$ \\
7 & 262 & 70 & 240 & 64 & $0,96 \mathrm{NS}$ \\
8 & 197 & 66 & 164 & 55 & $3,02 \mathrm{NS}$ \\
\hline Total & 1.189 & 69 & 1.059 & 61 & $7,52^{*}$ \\
\hline
\end{tabular}

$\chi^{2}$ crítico = 3,842, $(\alpha=0,05 ; 95 \%) ;(N S)$ não significativo; $\left(^{*}\right)$ significativo.

Tabela III. Número de ofertas de alimento oferecidas aos ninhegos pelas fêmeas e machos de Sula leucogaster, de outubro de 1998 a dezembro de 1999 e os respectivos resultados do teste qui-quadra $\left(\chi^{2}\right)$. Fases dos ninhos: 4 (um filhote recém-eclodido); 5 (dois filhotes recémeclodidos); 7 (um filhote com penugem pós-natal branca); 8 (um filhote com plumagem castanha e restos de penugem branca).

\begin{tabular}{|c|c|c|c|c|c|}
\hline Categorias & Fêmea & $\%$ & Macho & $\%$ & $\chi^{2}$ \\
\hline 4 & 10 & 8,3 & 8 & 6,7 & $0,22 \mathrm{NS}$ \\
\hline 5 & 0 & 0 & 1 & 0,8 & $1,00 \mathrm{NS}$ \\
\hline 7 & 32 & 26,7 & 21 & 17,5 & $2,28 \mathrm{NS}$ \\
\hline 8 & 31 & 25,8 & 17 & 14,2 & $4,08^{*}$ \\
\hline Total & 73 & 60,8 & 47 & 39,2 & $5,63^{*}$ \\
\hline
\end{tabular}

$\chi^{2}$ crítico = 3,842, $(\alpha=0,05 ; 95 \%) ;(N S)$ não significativo; $\left(^{*}\right)$ significativo.

mento $(n=5)$ e entre $10: 30$ e $11: 00$, com $4,9 \%$ das ofertas de alimento $(n=6)$. À tarde, as ofertas de alimento se intensificaram a partir das 15:30 e diminuíram depois das 17:30. Nesse período observaram-se aproximadamente $36 \%(n=43)$ das alimentações dos filhotes (Fig. 2).

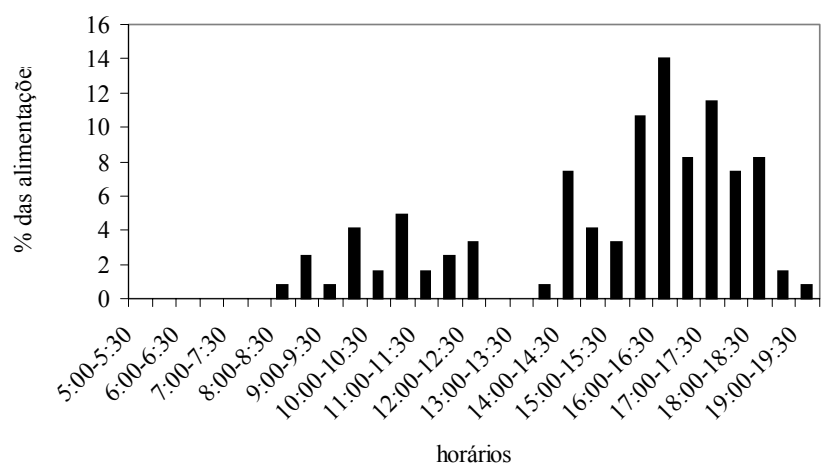

Figura 2. Intervalos de horários do dia em que foram observadas as ofertas de alimento aos filhotes, pelos adultos de Sula leucogaster, nas ilhas dos Currais, Paraná, de outubro de 1998 a dezembro de 1999.

\section{DISCUSSÃO}

WILSON (1975) listou as seguintes condições ecológicas relacionadas ao cuidado parental: 1) habitats saturados e estáveis - para um jovem animal estabelecer um território ou ser capaz de se reproduzir, é necessário ser socialmente experiente e eficiente em explorar recursos; a extensão da alimentação parental e da proteção, produz filhotes com maiores chances de serem bem-sucedidos numa alta densidade populacional; 2) ambientes físicos estressantes - alguns habitats são fisicamente tão extremos, que ovos e filhotes desprotegidos têm pouca chance de sobreviver; 3 ) dietas especializadas - algumas presas requerem métodos de captura que tornam necessário um longo período de aprendizagem antes do animal ficar independente; a ajuda dos pais nesse período é essencial; 4) pressão de predação - esta é provavelmente a principal razão operando para a evolução do cuidado parental.

Esses fatores ecológicos provavelmente moldaram, através da seleção natural, nos atobás-pardos, um período de cuidado parental de seis meses e meio, relativamente longo entre as aves. Nos atobás-pardos o investimento do macho foi selecionado para garantir um maior sucesso reprodutivo, isto é, a contribuição proporcional de indivíduos para as futuras gerações (BEGON et al. 1990).

Para BRUnTon (1988) o cuidado biparental ocorre quando: 1) a confiança da paternidade é alta para os dois sexos; 2) o

Revista Brasileira de Zoologia 20 (4): 583-589, dezembro 2003 
cuidado biparental aumenta significativamente o sucesso reprodutivo de ambos os sexos e; 3) a oportunidade de cruzamentos adicionais é limitada ou ausente. Uma estratégia para diminuir a possibilidade de cópulas extrapar e aumentar a confiança da paternidade nas ilhas dos Currais, pode ser a saída sincronizada entre a maioria dos indivíduos do mesmo sexo, podendo estar também relacionada a uma provável diferença no forrageamento entre os sexos.

Apesar dos machos também cuidarem da prole, o grau de investimento é diferente entre os sexos. Nas ilhas dos Currais pôde-se observar que a atividade de incubação foi mais executada pelas fêmeas. Entretanto os machos permaneceram mais tempo nos ninhos e as fêmeas se ausentaram mais, o que vai de encontro ao fato delas alimentarem mais os filhotes que os machos. Simmons (1970) observou em Ascension que as fêmeas realizaram cerca de 68\% das alimentações. Nelson (1978) também afirma que há evidências de que as fêmeas alimentam a prole mais que os machos, principalmente após a primeira semana de vida. Guerra \& Drummond (1995) observaram em Isla Isabel, na costa Pacífica do México, que machos e fêmeas de Sula nebouxii Milne-Edwards, 1882 alimentaram seus filhotes com freqüências similares nos dez primeiros dias, porém, nos 50 dias seguintes as fêmeas alimentaram os filhotes com maior freqüência, provendo duas a três vezes mais alimento que os machos. As fêmeas de $S$. nebouxii também chocaram cerca de $30 \%$ do tempo a mais que os machos (GUeRra \& DRUMmond 1995).

Os atobás-pardos apresentam dimorfismo sexual invertido no tamanho, ou seja, as fêmeas são maiores que os machos. O dimorfismo sexual no tamanho em aves parece ser correlacionado com aspectos do esforço reprodutivo (Ross 1979, Cabana et al. 1982). Segundo Mueller \& Meyer (1985) o dimorfismo sexual invertido no tamanho em aves pode ser uma conseqüência adaptativa dos diferentes papéis de machos e fêmeas no cuidado parental. A hipótese da divisão de trabalho afirma que machos e fêmeas têm funções diversas no cuidado parental e que a seleção natural atua diferentemente em cada sexo produzindo um tamanho corporal ótimo (Guerra \& DRumMOND 1995). Os resultados deste trabalho corroboram essa hipótese.

Não é possível afirmar qual a pressão seletiva para os tamanhos diferentes ou para essa diferenciação no investimento parental para os atobás-pardos. Entretanto é provável a relação entre o maior tamanho da fêmea, o maior investimento da fêmea em incubar e alimentar os filhotes e o fato das fêmeas se alimentarem de presas maiores que aquelas dos machos, este último aspecto segundo KoHLRaUCH (comunicação pessoal de observação feita nas ilhas Moleques do Sul, Santa Catarina).

Simmons (1970) relacionou a diferença de tamanho e proporções entre os sexos de $S$. leucogaster com o comportamento alimentar; os dois sexos divergem nas técnicas de caça (e talvez no tipo de presa apanhada) e desta maneira reduzem a competição intraespecífica. A fêmea, maior que o macho, é capaz de mergulhar mais profundamente, enquanto o macho é mais ágil e versátil ao mergulhar. Segundo GuERRA \& DrumMOND (1995) os machos de $S$. nebouxii são menos eficientes que as fêmeas na provisão de alimento aos filhotes.

TRIVERS (1972) afirma que qualquer disparidade sexual no esforço parental irá causar um nível de competição para o sexo que investe menos, proporcional ao investimento excedido pelo sexo oposto; esse grau diferencial de seleção sexual tem conduzido à evolução das diferenças sexuais.
A seleção sexual, entendida como a reprodução diferencial não aleatória de indivíduos, resultante do acesso diferencial a parceiros ou a gametas (THORNHILl 1986), pode também influenciar padrões de cuidado parental (MAYNARD SMITH 1977, Clutton-Brock 1991). Para ANDERSSON (1994) os fatores que influenciam diretamente o investimento parental relativo de machos e fêmeas, são a força da seleção sexual nos traços fenotípicos e a ecologia da espécie.

O modelo de investimento parental ótimo prediz que acima de determinadas condições, machos devem diminuir o investimento em resposta à menor certeza da paternidade (Kempenaers et al. 1998). De acordo com a hipótese da certeza da paternidade de Trivers (1972), onde o investimento parental é correlacionado à probabilidade de relação genética entre pais e prole, é esperado que as fêmeas invistam mais na prole que os machos.

Apesar da diferença entre os sexos no cuidado parental dos atobás-pardos, os resultados obtidos mostram uma variação no investimento parental, principalmente em função da fase de desenvolvimento dos ninhos, isto é, em função das necessidades primordiais dos filhotes em cada fase do ciclo reprodutivo. Nas primeiras fases, com ovos (fases um e dois), foi observada uma alta porcentagem de falência; os ovos estão mais sujeitos à predação e à falência pelas intempéries (como chuvas, ventos e marés), principalmente pelo fato do ninho ser no solo. As baixas freqüências de ausência de ambos os pais demonstram o grande investimento em vigilância e proteção nessas fases. Entretanto, nesse período ainda é possível continuar o ciclo reprodutivo, após uma perda dos ovos; porque as fêmeas são capazes de iniciar uma nova postura.

Nas fases seguintes, já com filhotes recém-eclodidos (fases três, quatro e cinco), é fundamental a vigilância e permanência dos pais, o que foi evidenciado pela presença em 100\% do tempo de observação de pelo menos um dos pais no ninho e pela agressividade dos mesmos em relação a invasores na colônia. Nessas fases iniciam-se as alimentações, mas a exigência principal dos ninhos para se obter sucesso é a vigilância e a proteção. O gasto de energia e tempo já é maior, comprometendo o ciclo reprodutivo se houver falência nessas fases. Uma ninhada cresce em valor reprodutivo com o tempo, porque terá maior probabilidade de sobreviver até a idade reprodutiva e, portanto é condizente um maior investimento nas fases finais (HuntingFord \& TURNer 1987).

Após o filhote empenar-se o principal investimento é na alimentação dos mesmos. As ofertas de alimento aumentam significativamente a partir da fase sete. Nas espécies de aves altriciais, ou seja, que dependem de cuidado parental, o período entre o primeiro vôo do ninho e a parada do investimento parental, no qual o jovem depende parcialmente ou inteiramente de alimento dos pais, é um importante estágio no desenvolvimento das aves; nesse período a energia é armazenada e os jovens desenvolvem habilidades para forragear, essenciais para a sobrevivência (WeATHERs \& Sullivan 1989). A natureza crítica dessa fase é refletida pela alta taxa de mortalidade (BustamANTE 1994). É provável que o conflito de interesses entre os pais e os filhotes se inicie neste período (Arroyo et al. 2002). Se o filhote tenta maximizar sua probabilidade de sobrevivência, demandará maior investimento dos pais, gerando conflito (TRIVERS 1974). Variações nas condições alimentares devem influenciar a decisão dos pais em continuar ou não a alimentação dos filhotes, os quais já estão aptos a voar e obter seu próprio alimento.

Revista Brasileira de Zoologia 20 (4): 583-589, dezembro 2003 
Dados de outros autores (Dorward 1962, NeLSON 1978, Simmons 1967, 1970, Bege \& Pauli 1989, Marchant \& Higgins 1990) a respeito da biologia de $S$. leucogaster, retratam padrões de comportamento muito semelhantes aos encontrados nas Ilhas dos Currais. Algumas diferenças se devem a fatores ecológicos, próprios de cada lugar, por exemplo, o tempo em que os pais ainda cuidam dos filhotes aptos ao vôo. A disponibilidade de alimento parece ser o principal regulador desses padrões.

A quantidade de tempo e energia investidos e o nível de risco, em qualquer esforço reprodutivo são dependentes do valor da tentativa reprodutiva naquele momento e do valor reprodutivo futuro dos pais (Trivers 1974, Dawkins 1979). Provavelmente a redução da ninhada ocorra pelo alto custo da criação de dois filhotes numa mesma estação reprodutiva, principalmente relativo à alimentação. $\mathrm{O}$ investimento com alimentação aumenta na fase sete, com apenas um ninhego, sendo que a redução ocorre na fase anterior. Não foi observado nenhum ninho na fase seis (um filhote com penugem pósnatal branca e um filhote recém-eclodido); a redução da ninhada ocorre na fase cinco (com dois filhotes recém-eclodidos), portanto, a redução evoluiu nesta espécie para ocorrer antes dos ninhegos emplumarem-se.

Além disso, um investimento alto em criar dois filhotes ao mesmo tempo, possivelmente comprometeria a sobrevivência e a reprodução futuras dos adultos e dos filhotes. Como os atobás-pardos reproduzem-se continuamente, a estratégia reprodutiva parece ser a criação de apenas um filhote a cada oito meses e, portanto, ao final de dois anos um casal poderá ter criado três filhotes.

\section{AGRADECIMENTOS}

Os autores agradecem ao Centro de Estudos do Mar/UFPR pelo apoio logístico, à FAPESP pela bolsa de mestrado concedida; aos biólogos Ricardo Krul, Valéria Moraes, Nelson Novaes, Márcia Regina de Oliveira e João Teixeira Neto pelo apoio em campo e sugestões; à Mariana Cariello e ao Tarcísio pela revisão do artigo.

\section{REFERÊNCIAS BIBLIOGRÁFICAS}

Andersson, M. 1994. Sexual Selection. Princeton, Princeton University Press, 599p.

Arroyo, B.E.; T.H. De Cornulier \& V. Bretagnolle. 2002. Parental investment and parent offspring conflicts during the post fledging period in Montagu's harriers. Animimal Behaviour, London, 63 (2): 235-244.

Bateman, A. J. 1948. Intrasexual selection in Drosophila. Heredity, Essex, 2: 349-368.

Bege, L.A.R. \& B.T. Pauli. 1989. As aves nas ilhas Moleques do Sul - Santa Catarina: aspectos da ecologia, etologia e anilhamento de aves marinhas. Florianópolis, Fundação do Meio Ambiente, 61p.

Begon, M.; J.L. Harper; C.R. Townsend. 1990. Ecology: individuals, populations and communities. Massachusetts, Blackwell Science, 945p.

Bustamante, J. 1994. Family break-up in black and red kites Milvus migrans and M. milvus: is time of independence an offspring decision? Ibis, London, 136: 176-184.

BRUNTON, D.H. 1988. Sexual differences in reproductive effort: time-activity budgets of monogamous killdeer, Charadrius vociferous. Animal Behaviour, London, 36: 705-717.

Cabana, G.; A. Frewin; R.H. Peters \& L. Randall. 1982. The effect of sexual size dimorphism on variations in reproductive effort of birds and mammals. The American Naturalist, Chicago, 120: 17-25.

Clutton-Brock, T.H. 1991. The Evolution of Parental Care. Princeton, Princeton University Press, 368p.

Dawkins, R. 1979. O Gene Egoísta. São Paulo, Ed. Itatiaia, Ed. Universidade de São Paulo, 230p.

Dorward, D.F. 1962. Comparative biology of the white and brown booby Sula spp of Ascension. Ibis, London, 103b: 174-220.

Grier, J.W. \& T. BURK. 1991. Biology of animal behavior. Missouri, Mosby - Year Book, Inc., 890p.

Guerra, M. \& H. Drummond. 1995. Reversed sexual size dimorphism and parental care: minimal division of labour in the blue-footed booby. Behaviour, Leiden, 132 (7-8): 479496.

Huntingford, F. \& A. Turner. 1987. Animal Conflict. New York, Chapman and Hall, 448p.

IBGE. 1992. Manual técnico da vegetação brasileira. Rio de Janeiro, IBGE, Série Manuais Técnicos em Geociências, 466p.

Kempenaers, B.; R.B. Lanctot \& R.J. Robertson 1998. Certainty of paternity and parental investment in eastern bluebirds and tree swallows. Animal Behaviour., London, 55 (4): 845-860.

LACK, D. 1968. Ecological Adaptations for Breeding in Birds. London, Methuen, 409p.

Marchant, S. \& P.J. Higgins. 1990. Handbook of Australian, New Zealand \& Antartic Birds. Melbourne, Oxford University Press, vol. 1, 735p.

Martin, P. \& P. Bateson. 1986. Measuring Behaviour - an introductory guide. New York, Cambridge University Press, 200p.

Maynard SMITH, J. 1977. Parental investment: a prospective analysis. Animal Behaviour, London, 25: 1-9.

MMA. 2002. Avaliação e identificação de áreas e ações prioritárias para a conservação, utilização sustentável e repartição dos benefícios da biodiversidade nos biomas brasileiros. Brasília, Ministério do Meio Ambiente/SBF, 404p.

Mueller, H.C. \& K. Meyer. 1985. The evolution of reversed sexual dimorphism in size - A comparative analysis of the Falconiformes of the Western Paleartic. Current Ornithology, New York, 2: 65-101.

Nelson, J.B. 1978. The Sulidae - Gannets and Boobies. Oxford, Oxford University Press, 1012p.

Ross, H.A. 1979. Multiple clutches and shorebirds egg and body weight. The American Naturalist, Chicago, 113: 618-622.

SICK, H. 1997. Ornitologia Brasileira. Rio de Janeiro, Editora Nova Fronteira, 912p.

Simmons, K.E.L. 1967. Ecological adaptations in the life history of the Brown Booby at Ascension Island. Living Bird, Ithaca, 6: $187-212$.

. 1970. Ecological Determinants of Breeding Adaptations and Social Behaviour in Two Fish-eating Birds, 3777p. In: J.H. Своок (Ed.). Social Behaviour in Birds and Mammals. London, Academic Press, 492p.

ThorNhILL, R. 1986. Relative parental contribution of the sexes to their offspring and the operation of sexual selection, $p$. 
113-136. In: M.H. Nitecki \& J.A. Kitchell (Eds). Evolution of Animal Behavior: Paleontological and Field Approaches. New york, Oxford University Press, 184p.

Trivers, R.L. 1972. Parental investment and sexual selection, p.136-179. In: B. CAmpbell (Ed.). Sexual Selection and the Descent of Man. Chicago, Aldine, 378p.

. 1974. Parent-offspring conflict. American Zoologist, Thousand Oaks, 14: 249-264.
Weathers, W.W. \& K.A. Sulliva. 1989. Juvenile foraging proficiency, parental effort, and avian reproductive success. Ecologogical Monographs, Lawrence, 59: 223-246.

Wilson, E.O. 1975. Sociobiology: the new synthesis. Massachussets, Belknap/Harvard University Press, Cambridge, 366p.

ZAR, J.H. 1999. Biostatistichal analysis. New Jersey, Prentice Hall, 663p.

Recebido em 24.VIII.2002; aceito em 08.X.2003. 